\title{
An Opinion Survey on Medical Education Technologies Prevalent And Innovative
}

\author{
Ramakristna Sahu ${ }^{1}$,Sadananda Rath ${ }^{2}$, Bandana Rath $^{3}$, Suchitra Panigrahi $^{4}$ \\ ${ }^{1}$ Associate Professor, Department Of Anatomy, MKCG Medical College \\ ${ }^{2}$ Professor And Head, Department Of Anatomy, MKCG Medical College \\ ${ }^{3}$ Associate Professor, Department Of Pharmacology, MKCG Medical College \\ ${ }^{4}$ Assistant Professor, Department Of Ophthalmology, MKCG Medical College, Berhampur,Odisha
}

\begin{abstract}
The aim of the study is to find a suitable teaching method that focuses on both students and teachers and that focuses on both students and teachers and that yields the best out of the teaching learning process. A cross-sectional study on 168 MBBS students of different semesters conducted with a well structured questionnaire and the results were analyzed. There has been more students opting for audio visually aided teaching and participatory group discussion type of learning. However, majority of the students preferred an integrated method combining the traditional class room didactic teaching as well as the other modern teaching aids. To captivate, students attention during the total process of teaching, which is the key to the process of learning, the students suggested the class be interactive and be followed by a test on the topic.
\end{abstract}

Keywords: Group Discussion, Lecture, Medical Education, Seminars, Tutorials

\section{Introduction}

To bring home a student in any subject has been task demanding the necessary art, skill and planning, may it be learning anatomy the portal of entry for students into medical studies or be it any subject of medicine. The plethora of information a learner has to master and conceptualize the structure in terms of function within the stipulated time frame has been the challenge faced by the students. And to effectively impart to knowledge has been challenge faced by the teachers with the constraints of time and the number of available teaching staff. A major factor that vitally matters is the student and teacher ratio especially where the intake of students is 150 or even 250 per a batch.

To cater a quality teaching, the teaching-learning methodology needs to be streamlined and update time to time. A valuable step in this process to gather feedback from the students with the help of a well-structured questionnaire, analyze their opinion and restructure the teaching method. Over the last few years there been a paradigm shift from a teacher-centric to student-centric method of teaching. Each has its benefits and drawbacks that need to be scrupulously calibrated and employed in practice. In the age old teacher-centric teaching the teacher is on focus whose preparedness on the topic, his personality, control on classroom activities are the main guiding factor in imparting knowledge. Apart from being easy in economical in delivery of knowledge ${ }^{[1,2,3]}$ to a larger number of students, it helps not to miss any point; the class runs in an orderly manner, students are quiet and receptive. However the effectiveness of this method depends more on the experience and skill of the teacher. Also the students exclusively listen and imbibe the knowledge. It is more of a one-way process.

Learning becomes more effective if the method involves more of a participatory type of teaching ${ }^{[4]}$ .During this process of teaching the teacher comes to know the receptivity of the student more efficiently and streamlines his didactic delivery further. It becomes a two way process. It encourages students to build up their imagination and conceptualization of the facts. Prior to the age of internet the traditional teacher and the books were the sources of information. But currently when all the information is available to the taught at their fingertips this two-way teaching mode seems to be the method of choice. However, the teacher must play the vital role for the holistic assimilation of the curriculum by the students.

Truly, teaching without learning is futile ${ }^{[5]}$. Attention of both the teacher and taught get focused on the improvement of learning during classroom assessment and teaching becomes an every evolving process ${ }^{[6]}$. Learning style is the manner and the condition in which the learners efficiently perceive, process, store and recall what they attempt to learn ${ }^{[7]}$.It is the preferred method of accumulating, processing, interpreting and analyzing information ${ }^{[8]}$. However teaching and learning are the two sides of the same coin ${ }^{[9]}$. In this method both the teacher and the taught are in focus. They interact equally. A group work in encouraged. Students collaborate and communicate with each other and also with the teacher. Learning process becomes a flexible learning, experiential learning, a self-directed learning. Such learning guides the student to be a perpetual leaner. He looks for a solution without fully depending on the teacher ${ }^{[10,11]}$

In the co-operative learning method students produce questions. Teacher acts as facilitator in the debate, based on the enquire, the fundamental information and the possible solutions to the questions are found 
out. The present work has been taken up in MKCG Medical College, Berhampur to study the preference of the students of the method of teaching and learning approach, currently in practice in to find out the much needed modification as per their response.

\section{Aim Of Study}

1. To find out a suitable teaching approach from the student point of view and to suggest it into present teaching methodology,

2. To study and to establish a healthy environment in the teaching institution.

3. To allow them to express their values on the present methodology of teaching and learning.

\section{Material \& Method}

This was a descriptive cross-sectional study carried out on 168 students of MBBS students of M.K.C.G. Medical College, Berhampur from Dt.12.01.2017 to Dt.25.05.2017 students of all the semesters are included except $1^{\text {st }}$ and $2^{\text {nd }}$ professional as they are least exposure to the college environment to express their views. A questionnaire was prepared, pre validated by Senior Faculty members and distributed among the students for answering. Prior approval was obtained from the institutional Ethics Committee for the above purpose. Students were well informed about the purpose of study and questionnaire. ${ }^{[13-15]}$ They were assured about the confidentiality of response given through the questionnaire; and asked to respond freely \& fearlessly and instructed not to reveal their identity at all. The replied questionnaires were collected and data were noted in MS Office Excel. Descriptive statics on the data were performed.

\section{Observation \& Results}

Out of 168 medical students of all the semester distribution of male student $106(63 \%)$ and female students 62 (37\%) were taken for observation and the fallowing result was obtained.

\section{Teaching Environment:}

In the medical college the students built of their carrier by staying the period of 5 to 6 years to complete MBBS course. For this the environment of such five year stay period is important factor of influence the mentality of future doctors. More number of students still agreed and satisfied with present system of entrance test with the basic qualification of +2 sciences and one year of $1^{\text {st }}$ professional MBBS course. Different colleges of different disciplines have adopted dress code and day to day life style to maintain same discipline among the student but our student suggested it unnecessary most the medicos suggest for 2 weeks period for better accommodation and familiarity in the college environment to establish themselves comfortable. Though the physical exercise is essential for better health but $39.88 \%(n=67)$ of students are not getting time in the present system. But as lunch period is concern the majority of student $68 \%(n=115)$ were satisfied with the one hour break.

\section{Teaching Method:-}

Most of the students $81.55 \%(n=137)$ opted for provision of both readymade notes and question bank at end of each class. A few $8.9 \%(n=15)$ suggested for the readymade note only and question bank only of 9.25\% ( $\mathrm{n}=16)$. Again at the end of each chapter $72.2 \%(\mathrm{n}=121)$ preferred for conducting a test examination. $64.88 \%(n=109)$ of them suggested for asking question in between the lecture class to make it interactive. For most effective session $48.81 \%(n=82)$ of student optioned, there should be a combined of lecture, tutorial, group discussion and seminar \& only $29.17 \% \quad(n=49)$ suggested for lecture class is a affective method. Interestingly $1.7 \%(n=3)$ of students prefer academic based teaching and $29.76 \%(n=50)$ opted practical/clinical based teaching and majority $68.45 \%(n=115)$ opted both. Again $90.48 \%(n=152)$ of all suggested a combined interactive student seminar of non clinical, para-clinical and clinical seminar on same related topic to have a better impact. $92.86 \%(n=156)$ student have suggested that a compulsory teaching on "Basic Hospital management and administration" is essential for future need as they might be posted any hospital to manage independently $70.83 \%(n=119)$ of student felt that ability of teacher can be improved by students confidential feedback suggestion to the concern teacher.

\section{Teaching Tool:-}

$69.64 \%(n=117)$ of student felt that both chalk and talk and audio-visual aid have better impact in teaching than audio-visual presentation $10.12 \%(\mathrm{n}=17)$ alone (fig-1). 52.98\% ( $\mathrm{n}=89)$ of students prefer both class notes and text book and where as $47.02 \%(n=79)$ Students felt that text book is sufficient enough to understand as theory subject concern. Which shows that present available text book were made easier to understand? $80 \%$ student felt that senior teacher should take theory class as their lecture are worth listening than junior teacher. 
Table: 1 Suggested modification for classroom Lecturer/ Teachings by students

\begin{tabular}{|c|c|c|c|}
\hline \multicolumn{2}{|c|}{ Modification } & Number & $\begin{array}{l}\text { Percentage } \\
(\%)\end{array}$ \\
\hline 1) & $\begin{array}{ll}\text { At the end of teaching } \\
-\quad \text { Readymade note } \\
-\quad \text { Question bank } \\
\text { - } \quad \text { Both } \\
\end{array}$ & $\begin{array}{l}15 \\
16 \\
137\end{array}$ & $\begin{array}{l}8.93 \\
9.50 \\
81.55\end{array}$ \\
\hline 2) & $\begin{array}{l}\text { Text examination at the end of chapter } \\
-\quad \text { Yes } \\
-\quad \text { No }\end{array}$ & $\begin{array}{l}121 \\
47\end{array}$ & $\begin{array}{l}72.02 \\
27.98\end{array}$ \\
\hline 3) & $\begin{array}{l}\text { Asking questions in between the Lecturer } \\
\text { - Yes } \\
-\quad \text { No }\end{array}$ & $\begin{array}{l}109 \\
59\end{array}$ & $\begin{array}{l}64.88 \\
35.12\end{array}$ \\
\hline 4) & $\begin{array}{ll}\text { Effective teaching method } \\
\text { - } & \text { Lecturer class } \\
\text { - } & \text { Tutorial class } \\
\text { - } & \text { G.D. } \\
\text { - } & \text { Seminar } \\
\text { - } & \text { All the above }\end{array}$ & $\begin{array}{l}49 \\
25 \\
1 \\
11 \\
82\end{array}$ & $\begin{array}{l}29.17 \\
14.88 \\
0.60 \\
6.55 \\
48.81\end{array}$ \\
\hline 5) & $\begin{array}{l}\text { Compulsory teaching on Basis Hospital management and } \\
\text { administration } \\
\text { - Yes } \\
\text { - No }\end{array}$ & $\begin{array}{l}156 \\
12\end{array}$ & $\begin{array}{l}92.86 \\
7.14\end{array}$ \\
\hline 6) & $\begin{array}{ll}\text { Preferable teaching } \\
-\quad \text { Academic based } \\
\text { - } \quad \text { Practical / clinical based } \\
\text { - } \quad \text { Both } \\
\end{array}$ & $\begin{array}{l}3 \\
50 \\
115\end{array}$ & $\begin{array}{l}1.79 \\
29.76 \\
68.45 \\
\end{array}$ \\
\hline 7) & $\begin{array}{l}\text { Combined interactive seminar of non clinical, Para-clinical \& } \\
\text { clinical } \\
\text { - Yes } \\
-\quad \text { No }\end{array}$ & $\begin{array}{l}152 \\
16\end{array}$ & $\begin{array}{l}90.48 \\
9.52\end{array}$ \\
\hline
\end{tabular}

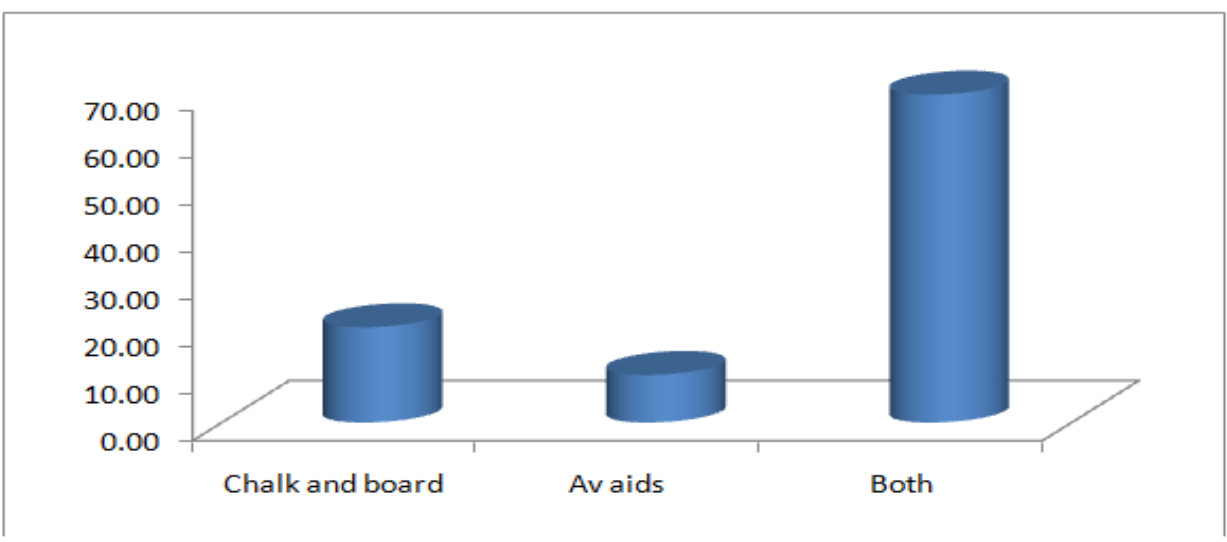

Fig-1: Students' view on the best teaching tool

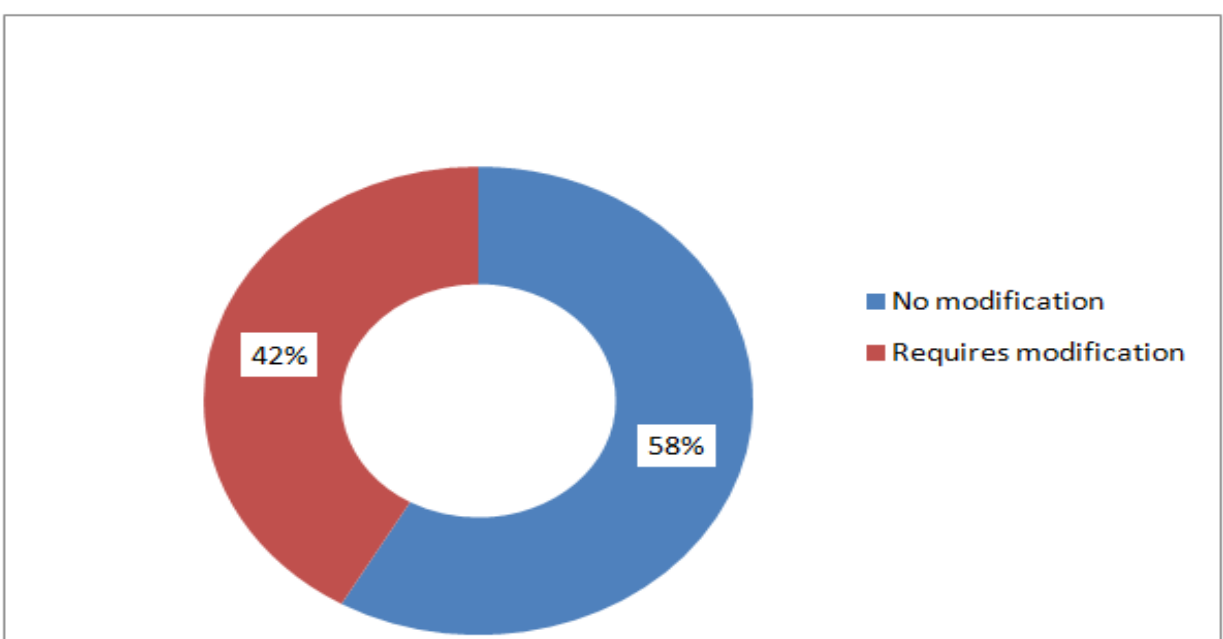

Fig-2: Overall opinion of students on the modification of present method of teaching 


\section{Discussion}

Medical education is a special type of education which takes care of the students to acquire the professional skill with humanity and sincerity. The changing social environment influences the lifestyle and learning attitude of the medical students at this present time. So, medical education system should change as per the acceptability of students with an affective maximum qualitative output. The growing knowledge and application of information and technology may be utilized in the field of medical education to upgrade standard teaching standard. So e-learning and web casting should be taken (incorporated) onto as one of our teaching tools besides the latest traditional teaching of chalk and talk which have not lost its importance yet. The increase population in a great burden to provide health facility to fulfill the goal of health for all the population and the doctor ration is not satisfactory to meet the health problem.

The present time needs more number of doctors to be trained and more medical colleges to be established for the above purpose. The medical teaching should be a holistic one. The doctor should have a complete knowledge regarding self development and nationality by which one can understand the problem of individual and society as whole. Now a days it is seen that there is an increasing incidence of tussle between the system and public. The medicos are not able to handle the present problems. The expectation of the society is high enough for which a special attention to be develop it in our medical education system. To meet the problems the medical curriculum should modify in response to the students, faculty and public initiative to improve the basis health care system. The teaching is not a purely one way passage of knowledge from teacher to students but it should be also from other side as well as to invite the thoughts and feelings of the students. The teacher should create an environment of faithfulness and fearlessness among the students. For this the teacher should play a key role for the alarmed development of students.

Our findings in the present survey showed that most of students opted for provision of both readymade notes and question bank at the end of each class. At the end of each chapter, conducting a test examination was suggested by majority of students. To make the class more interactive most of the students suggested to ask questions in between and they need both practical / clinical based teaching. Overall most of the students opted for a combination of Lecturer class, Group Discussion (GD), Seminar, tutorial session for better understanding (Table-1). Hence majority of them are satisfied with the present teaching method (fig-2). Our observation corroborate with that of Misal DD et al 2016. ${ }^{[13]}$ Several other studies also reported the feedbacks of students on teaching methodology and some also suggested for small group teaching method as a better strategy for better quality teaching. ${ }^{[16-20]}$

\section{Conclusion}

A combination of black board teaching with audiovisual aid, interacting sessions is choice of majority of students. However, further time to time students' feedback to improve our teaching learning method needs to be conducted.

\section{References}

[1]. Hafeez, K., Khan, M. L. Z., Jawaid, M., \&Haroon, S. Low attendance in lectures at medical colleges of Karachi - A cross sectional survey. Journal of Postgraduate Medical Institute. 2014; 28 (2): 161-164.

[2]. Sumera, A. Large group teaching, an effective and efficient teaching methodology. Journal of Asian Scientific Research. 2014; 4 (1), 1-5.

[3]. Held, S., \&McKimm, J. Improve your lecturing. British Journal of Hospital Medicine. 2009; 70 (8), $466-469$.

[4]. Irby DM. What clinical teachers in medicine need to know. Acad Med. 1994; 69: 333-342.

[5]. Angelo TA, Cross KP. Classroom Assessment Techniques: A Handbook for College Teachers. Second Edition. San Francisco: Jossey Bass Publishers, 1993.

[6]. Samarakoon L, Fernando T, Rodrigo C, Rajapakse S. Learning styles and approaches to learning among medical undergraduates and postgraduates. BMC Medical Education, 2013; 13: 42.

[7]. James WB, Gardner DL. Learning styles: Implications for distance learning. New Directions for Adult and Continuing Education, 1995; 67:19-31.

[8]. Kharb P, Samanta PP, Jindal M, Singh V. The Learning Styles and the Preferred Teaching-Learning Strategies of First Year Medical Students. Journal of Clinical and Diagnostic Research, 2013; 7 (6): 1089- 92.

[9]. Omorogiuwa TBE, Eweka HE. Integrating Teaching And Practice: Effective Teaching-learning In Social Work Education. Bangladesh Education Journal, 2012; 11 (2): 53-9.

[10]. Burnard P: Carl Rogers and postmodernism: Challenges in nursing and health sciences. Nurs Health Sci 1999; 1:241-247.

[11]. Taylor PG: Changing Expectations: Preparing students for Flexible Learning. The International Journal of Academic Development 2000, 5 (2):107-115.

[12]. Blanchard MR, Southerland SA, Granger EM. No silver bullet for inquiry: Making sense of teacher change following an inquirybased research experience for teachers. Sci Teacher Educ 2009; 93 (2): 322-60.

[13]. Misal Devika D, Maulingkar Saleel V, Meural A, D’ Mello, Rataboli P V. Students' opinion on prevailing and innovative methods in medical education technology and changes recommended. IJBCP. 2016;5:121-125

[14]. D. Vasundhara Devi, M. Kiran Deedi. "Teaching and Learning Methodology in Medical Education: An Analysis-in GSL Medical College, Rajahmundry, A. P”. Journal of Evolution of Medical and Dental Sciences 2015; 4 (72) September 07: 12557-12565.

[15]. Pramod B. Akat, Vitthal B. Karande, Mangala B. Murthy, Shreyas R. BuruteInterns opinion on 'bedside pharmacology clinics' and its incorporation in undergraduate curriculum. Journal of Pharmacology and Pharmacotherapeutics. 2012; 3 (1) :56-58 
[16]. Saleh, A. M., Al-Tawil, N. G., \& Al-Hadithi, T. Teaching methods in Hawler College of Medicine in Iraq: A qualitative assessment from teachers' perspectives. BMC Medical Education. 2012 s; 12:59

[17]. Shatzer J: Instructional methods. Acad Med 1998; 73: 538-45.

[18]. Walton H: Small group methods in medical teaching. Medical Education 1997; 31: 459-64.

[19]. Dinesh K. Badyal, Suman Bala, Prashant Kathuria. Student evaluation of teaching and assessment methods in pharmacology. Indian J Pharmacol.2010; 42 ( 2):87-89

[20]. George B. Carey, Farr A. Curlin and John D. Yoon.Medical student opinions on character development in medical education: A national survey. BMC Res Notes 2015; 8:455. DOI: 10.1186/s13104-015-1434-z 